\title{
Translation and adaptation of the physical activity enjoyment scale (PACES) in a sample of Portuguese athletes, invariance across genders nature sports and swimming
}

\section{Tradução e adaptação do physical activity enjoyment scale (PACES) numa amostra de atletas portuguesas, invariância entre géneros, desporto de natureza e natação}

\author{
Diogo Monteiro ${ }^{1,2}$ \\ Gilberto Nunes \\ Daniel Almeida Marinho $0^{2,3}$ \\ Nuno Couto ${ }^{1}$ \\ Raúl Antunes ${ }^{1}$ \\ João Moutão ${ }^{1,2}$ \\ Luís Cid ${ }^{1,2}$
}

\begin{abstract}
The aim of this study was to translate and validate of the Physical Activity Enjoyment Scale (PACES), from Mullen et al. version in Portuguese athletes, invariance across genders and nature sports and swimming, as well as, external validity, through the Portuguese version of BRSQ. Athletes ( $\mathrm{n}=1032 ; 273$ nature sports, 759 swimming) with an average age of 18,95 $\pm 6,59$ years participated in this study. Confirmatory factor analysis (maximum likelihood), multigroup analysis (measurement invariance) and correlation analysis were used for data analyzed. Results supported the suitability of the models (one factor which eight items) showing an adequate fit to the data in each sample (general: $\chi^{2}=181,96, p=<0,01$, $\mathrm{df}=20, \mathrm{SRMR}=0,04, \mathrm{NNFI}=0,94, \mathrm{CFI}=0,96, \mathrm{RMSEA}=0,07, \mathrm{RMSEA} 90 \% \mathrm{IC}=0,06-0,08$; male: $\chi^{2}=113,27, p=<0,01, d f=20, S R M R=0,04$, NNFI $=0,95$, CFI $=0,97$, RMSEA $=0,07$, RMSEA 90\% IC=0,06-0,08; female: $\chi^{2}=67,59, \mathrm{p}=<0,01, \mathrm{df}=20, \mathrm{SRMR}=0,03, \mathrm{NNFI}=0,94$, CFI $=0,96$, RMSEA $=0,07$, RMSEA 90\% IC $=0,06-0,09$; nature sports: $\chi^{2}=42,32, p=0,02$, $\mathrm{df}=20, \mathrm{SRMR}=0,037, \mathrm{NNFI}=0,96, \mathrm{CFI}=0,98, \mathrm{RMSEA}=0,06, \mathrm{RMSEA} 90 \% \mathrm{IC}=0,04-$ 0,08; swimming: $\chi^{2}=130,14, p=<0,01, d f=20, S R M R=0,04, \mathrm{NNFI}=0,94, \mathrm{CFI}=0,96$, RMSEA=0,07, RMSEA 90\% IC $=0,06-0,08)$, as well as, were invariant across genders and nature sports and swimming $(\Delta \mathrm{CFI} \leq 0,01)$. Enjoyment was, on the one hand, found to be positively and significantly correlated with identified regulation $(\mathrm{r}=0,82)$, integrated regulation $(r=0,62)$ and intrinsic motivation $(r=0,90)$. On the other, it was negatively and significantly correlated with amotivation $(r=-0,25)$ and external and introjected regulation $(\mathrm{r}=-0,42 ;-0,38)$, respectively. Those findings allow concluding that PACES can be used to measure enjoyment in the future studies, thus filling an existing gap to date.
\end{abstract}

Key words: Exercise; Motivation; Sports; Validation studies.
Resumo - O objetivo deste estudo foi a tradução e validação do Physical Activity Enjoyment Scale, a partir da versão de Mullen et al., numa amostra de atletas portugueses e a invariância entre gếneros, desportos de natureza e natação, bem como, comprovar critérios de validade externa através da versão portuguesa do BRSQ. Participaram neste estudo 1032 atletas 273 desporto natureza; 759 natação), com uma média de 18,95 $\pm 6,59$ anos de idade. Os dados foram analisados através de análise fatorial confirmatória (método da máxima verosimilhança), análise multigupos (invariância entre grupos) e análise correlacional. Os resultados suportam a adequação dos modelos (1 fator, oito itens), para cada uma das amostras (geral: $\chi^{2}=181,96, p=<0,01, d f=20, S R M R=0,04, N N F I=0,94$, $C F I=0,96, R M S E A=0,07, R M S E A 90 \% I C=0,06-0,08 ;$ masculino: $\chi^{2}=113,27, p=<0,01, d f=20$, $S R M R=0,035, N N F I=0,95, C F I=0,97, R M S E A=0,07, R M S E A$ 90\% IC=0,06-0,08; feminino: $\chi^{2}=67,59, p=<0,01, d f=20, S R M R=0,03, N N F I=0,94, C F I=0,96, R M S E A=0,07, R M S E A 90 \%$ $I C=0,06-0,09$; desporto de natureza: $\chi^{2}=42,32, p=0,02, d f=20, S R M R=0,037, N N F I=0,96$, $C F I=0,98, R M S E A=0,06, R M S E A$ 90\% IC $=0,04-0,08 ;$ nataça $0: \chi^{2}=130,14, p=<0,001, d f=20$, $S R M R=0,04, N N F I=0,943, C F I=0, .96, R M S E A=0,07, R M S E A$ 90\% IC=0,06-0,08), bem como, revelou ser invariante em função dos gêneros e das modalidades $(\triangle C F I \leq 0,01)$. O divertimento correlacionou-se positivamente com regulação identificada $(r=0,82)$, regulação integrada $(r=0,62)$ e motivação intrinseca $(r=0,90)$, e negativamente com a amotivação $(r=-0,25)$, regulação externa $(r=-0,42)$ e regulação introjetada $(r=-0,38)$. Estes resultados permitem-nos afirmar que a tradução e adaptação do PACES, pode ser utilizada com elevado grau de validade e fiabilidade na avaliação do divertimento em futuros estudos, suprimindo uma lacuna existente.

Palavras-chave: Esportes; Estudos de validação; Exercício; Motivação.
1 Escola Superior de Desporto de Rio Maior do Instituto Politécnico de Santarém. Rio Maior, Portugal

2 Centro de Investigação em Desporto, Saúde e Desenvolvimento Humano. Vila Real, Portugal

3 Universidade da Beira Interior, Covilhã. Portugal

Received: March 22, 2017 Accepted: November 28, 2017 


\section{INTRODUCTION}

Throughout the last decades, several researchers ${ }^{1}$ have shown that enjoyment is one of the main reasons for young people to participate in sports. In this sense, enjoyment has consistently been linked with continued participation in sport ${ }^{2}$, whereas lack of enjoyment is an important determinant of sports dropout ${ }^{3}$.

Motivated by these factors, enjoyment has been studied using several types of samples: children ${ }^{4}$, adolescents ${ }^{5}$, healthy adults ${ }^{6}$, elderly ${ }^{7}$, and in different age groups ${ }^{8}$ and has been applied in different domains, namely: education $^{9}$, sports ${ }^{1,10}$ and exercise ${ }^{2}$.

Sports enjoyment refers to a positive emotional response acquired from the sports experience ${ }^{11}$. This is reflected by feelings of fun and pleasure, which has been shown to be associated several times with the most autonomous types of motivation (identified regulation, integrated regulation, and intrinsic motivation), according to self-determination theor $y^{12}$. The literature seems to point this way: several researchers have shown that the more self-determined individuals show higher levels of enjoyment relative to the less self-determined individuals ${ }^{13}$.

However, the assessment of enjoyment does not have a consensus within the scientific community because there is not a uniform instrument available that provides a standardized assessment of enjoyment in context of physical activity and sports, mainly in younger adult and adult populations $^{7}$. So far, the researchers ${ }^{2,5,7}$ strategy has been an adaptation of the original Physical Activity Enjoyment Scale (PACES) ${ }^{14}$, or the adaptation of another scale from the original PACES ${ }^{5,7}$, specifically applied to the samples under respective study.

The original PACES (18 items/one factor) was developed by Kendzierski and DeCarlo ${ }^{14}$ for an adolescent sample and that evaluated the participants' self-perception of enjoyment during physical activity. However, when applied to other samples, the instrument was revealed to have problems with its factorial structure ${ }^{10}$. According to Marsh ${ }^{15}$, such factorial seems to be related to the items being written on a positive and negative scale and not a single construct, such as the global scale of self-esteem. Similar conclusions were reported by Motl et al..$^{5}$ and Moore et al. ${ }^{16}$, and more recently by Mullen et al. ${ }^{7}$ and Jekauc et al. ${ }^{4}$. However, the full questionnaire of PACES ${ }^{14}$ was only used in the Heesch et al ${ }^{6}$ Still, we must highlight that the authors ${ }^{6}$ did does not analysed the measurement model, they only analysed the internal consistency (Cronbach's Alpha).

With Motl et al. ${ }^{5}$ findings, a new version of PACES was created by cutting out two items from the original version because they were not relevant to the sample of study and the content of the other items was modified, thus acquiring a factorial structure of 16 items/ 1 factor, which showed good adjustment to the data, as well as to be invariant among different cultures ${ }^{5}$. Later this instrument was applied to other contexts and cultures and, the measurement model showed similar results ${ }^{8,16}$. However, 
in the Moore et al. ${ }^{16}$ study, the model was revealed to have a variation on the genders basis, and the authors advised analysing the invariance on future studies with the intention to assess the enjoyment perception on gender.

In the study conducted by Jeukac et al. ${ }^{4}$, in German language, the structure of measurement model was confirmed, and showed a good psychometric properties. However, partial invariance was showed, because the items were on the positive and negative scales ${ }^{4}$. Notwithstanding, these authors suggest that on future studies, only the items on either the positive or the negative should be used.

Later, Raedeke ${ }^{2}$ and McArthur and Raedeke ${ }^{9}$ used an eight items scale from the $\mathrm{PACES}{ }^{15}$ original version; yet, they neither performed an analysis of the psychometric properties nor demonstrated the measurement model adequacy. In the Raedeke ${ }^{2}$ study, the author used eight items selected by a panel of specialists and these eight items were then also used by McArthur and Raedeke ${ }^{9}$. These authors added that a scale so large was not needed to assess a single construct because according to Kline ${ }^{17}$ three items is the minimum number of items needed to saturate a latent factor.

More recently, Kendzierski and Morganstein ${ }^{1}$, supported by the evidence of Raedeke ${ }^{2}$ and McArthur and Raedeke, and used this eight-item scale on a structural equation model, adding enjoyment as an antecedent, which was advocated by Crocker et al. ${ }^{10}$ since this study was an extension of the model proposed by Kendzierski et al. ${ }^{18}$. Nevertheless this model was revealed to be an invariant across two analysed sports (cyclists and runners). However the psychometric properties of this version were not analysed and the measurement model structure was not confirmed.

Mullen et al. ${ }^{7}$ then developed a study where they reviewed the metric of depth to the psychometric properties of the original PACES version, as well as for the other existing versions; they proposed an alternative scale with eight items different from the version proposed by Raedeke ${ }^{2}$ that showed excellent values of adjustment as well as good psychometric properties . The Mullen et al. ${ }^{7}$ version, also revealed longitudinal invariance, across practitioners groups and over time showing that there were no differences regarding the enjoyment perception of enjoyment across groups. Based on Mullen et al. ${ }^{7}$ results that this newer version of PACES could be used with a high degree of validity and reliability by researchers assessing enjoyment, advising that other studies should be conducted in other samples so that the robustness of the measurement model could be confirmed, which was our choice for the present study.

Based on Mullen et al. ${ }^{7}$, suggestions, as well as the fact that none of the scales have been applied to the sports context before, besides the work of Crocker et al. ${ }^{10}$ when it did not show good psychometric properties, and on the absence of instruments that assess the enjoyment of the Portuguese population. Thus, the present study purposes the following: (i) translate and validate to the Portuguese population a version of PACES from Mullen et al. ${ }^{7}$ (ii) measurement invariance across genders and sports (nature sports and swimming); (iii) verify the external validity assumptions through a 
correlational analysis between PACES and BRSQp (Behavioural Regulation Sport Questionnaire-Portuguese version) founded on the theoretical assumptions of the self-determination theor $y^{12}$, as well as previously identified theoretical support.

\section{METHODOLOGICAL PROCEDURES}

\section{Participants}

\section{- General sample}

The sample comprised 1032 federated athletes (707 males, 325 females) from nature sports (273) and swimming (759), aged between 12 and 44 years $(M=18,95 ; D P=6,59)$. In this sample, the years of practice varied from 1 to 28 , the number of weekly training from 1 to 11 , and the duration of the training sessions from 60 to 180 minutes per day.

\section{- Nature sports sample}

The sample comprised 273 federated athletes ( 220 males, 53 females), aged between 21 and 44 years $(M=18,28 ; \mathrm{SD}=4,89)$. In this sample, the years of practice varied from 1 to 28 , the number of weekly training from 1 to 11 , and the duration of training sessions from 60 to 180 minutes per day.

\section{- Swimming sample}

The sample comprised 759 swimmers (487 male, 272 female), aged between 12 and 20 years $(M=15,41 ; S D=2,41)$. In this sample, the years of practice varied from 6 to 14, the number of weekly training from 4 to 11, and the duration of training sessions from 120 to 180 minutes per day.

\section{Instruments}

Physical Activity Enjoyment Scale (PACES) 7 . This questionnaire, in its original version, was comprised of 18 items with a seven-point bipolar scale. However, in this study y Mullen et al.7 version was used. This version was comprised of eight items and one factor. In this study a five-point Likert scale used, which varied between 1 ("Strongly Disagree") and 5 ("Strongly Agree"), similar to Motl et al. ${ }^{5}$ and Moreno-Murcia et al. ${ }^{8}$. The items were grouped posteriorly into one factor which reflected the enjoyment of the subjects.

Behavioral Regulation Sport Questionnaire (BRSQ ${ }^{19}$, Portuguese version $^{20}$. This was used to prove the external validity of the PACES ${ }^{7}$. This questionnaire consisted of 24 items with a seven-point Likert scale which varied between 1 ("Nothing true for me") and 7 ("Totally true for me"). The items were grouped into six factors (four items each), which reflected the underlying SDT continuum ${ }^{12}$. In the present study, this questionnaire showed a good internal consistency with high values of Composite Reliability: amotivation $(\mathrm{CR}=0,90)$, external regulation $(\mathrm{CR}=0,91)$, introjected regulation $(\mathrm{CR}=0,89)$, identified regulation $(\mathrm{CR}=0,74)$, integrated regulation $(\mathrm{CR}=0,81)$ and intrinsic motivation $(\mathrm{CR}=0,89)$, such as recommended by Hair et al. ${ }^{21}$. 


\section{Procedures}

\section{- Data collection}

Every athlete and/or legal guardian was contacted individually by telephone in which, in addition to the explanation of the study's purposes, was requested an e-mail address to send the questionnaire. Each e-mail was sent, individually, with a different link for each subject, assuring they would only receive the e-mail once, so as an intentions letter with the research purposes properly signed by all its authors, in which confidentiality principle was safeguarded. The questionnaires were filled through the survey monkey platform, with a mean filling time of 12 minutes. Ethical approval was obtained from the ethics and scientific board of the University of Beira-Interior, Portugal.

\section{- Translation of Questionnaire}

For the translation and adaptation of the instrument from the original language (English) to Portuguese, methodological procedures suggested by Vallerand ${ }^{22}$ were adopted. However, instead of the translation/back translation technique proposed by Vallerand ${ }^{21}$, the committee approach methodology was used. The process was developed in five stages: (1) Preliminary Translation: this first stage was made by the researchers with the help of three translators, with academic education in English-Portuguese, and from this resulted the first version of the questionnaire (2) First Committee: the analysis/evaluation of the initial version was realized individually by a panel composed by four specialists from different areas of the scientific background (Portuguese-English, Psychology, Sports Psychology, Sports Sciences). From the changes suggested, turned the second version of the questionnaire (3) Second Committee: second version of the questionnaire was once again submitted to an analysis/evaluation from another panel (different from the previous stage), this time composed by four specialists (Psychology, Sports Psychology, Sports Sciences). This stage was over only when all the specialists agreed with each other and the opinion of the member of the panel was unanimous towards the item contents of the new version of the questionnaire (3rd version); (4) Pilot Study: elaboration of the first layout of the instrument, and application of the 3rd version to 50 subjects (higher education students from the areas of Sport Science, Nature Sports, Exercise Psychology, and Sports Training), to analyse and determine the understanding difficulties and interpretation of the items content. From this stage resulted the 4th version of the questionnaire and (5) Final Review: review of the Portuguese (syntax aspects - spelling, grammar and phrase construction), realized by two Portuguese professors, and elaboration of the final layout of the questionnaires (final version).

\section{Statistical Analysis}

To undertake the Confirmatory Factor Analysis (CFA), the recommendation of a 15:1 ratio was considered ${ }^{17,21,23}$, because the normalized 
estimate of Mardia's coefficient of multivariate kurtosis was greater than 5,0 in all samples: general sample $(85,90)$, male sample $(92,91)$, female sample $(82,87)$, nature sports sample $(81,71)$ and swimming sample $(90,66)$. As such, the data analysis was undertaken according to the recommendations of several authors ${ }^{17,21,23}$ : estimated method of maximum likelihood, chi-squared $\left(\chi^{2}\right)$ testing of the respective degrees of freedom (df) and the level of significance (p) and the following adjustment goodness-of-fit indexes were also used: Standardized Root Mean Square Residual (SRMR), Comparative Fit Index (CFI), Non-Normed Fit Index (NNFI), Root Mean Square Error of Approximation (RMSEA) and the respective confidence interval (90\% CI). Traditionally, NNFI and CFI values $\geq 0,90$ and RMSEA and SRMR $\leq 0,08$ have been used as cut-off criteria ${ }^{21,23,24}$. Additionally, convergent validity was analysed (to check if the items were related to the respective factor) via the calculation of the average variance extracted (AVE), considering values of $A V E \geq 0,50^{21}$ and the composite reliability $(\mathrm{CR})$ was analysed to assess the internal consistency of the factors, adopting $\mathrm{CR} \geq 0,70$ as the cut-off values ${ }^{21}$. Finally, to check the assumptions of the external validity of PACES, Pearson correlation ( $r$ ) was used between PACES and the different types of motivation underlying SDT framework ${ }^{13}$ : amotivation, external regulation, introjected regulation, identified regulation, integrated regulation and intrinsic motivation. The significant level adopted was $\mathrm{p} \leq 0,05$. The analyses were undertaken using AMOS and SPSS 20.0.

\section{Multi-group analysis}

A multi-group analysis, is one of the crucial aspects of the development and use of psychometric instruments ${ }^{25}$, because it demonstrates if the measurement model structure was equivalent (invariant) across different groups with different characteristics, in present study across (nature sports vs swimming) and (male vs female).

Accordingly several authors ${ }^{23,25}$, for invariance to exist, it is necessary to verify two criteria's: 1) the measurement model should be adjusted in to each group; 2) to perform a multigroup analysis, it is necessary to examine the following invariance types: configural invariance (without equality constraints); metric invariance (constraining factor loadings equal); strong invariance (constraining both factor loadings and item intercepts equal concurrently) and strict invariance (constraining factor loadings, item intercepts, and item residuals concurrently equal). According to Cheung and Rensvold ${ }^{25}$, the difference in values between the unrestricted model (free parameters) and the restricted model (fixed parameters) should be $\Delta \mathrm{CFI}$ $\leq 0,01$. In line with Cheung and Rensvold ${ }^{25}$, determining invariance in multi-sample testing using the $\Delta \chi^{2}$ value has been considered unsatisfactory. From this perspective, Cheung and Rensvold ${ }^{26}$ revealed that decisions should be based on CFI differences ( $\Delta \mathrm{CFI})$. 


\section{RESULTS}

\section{Preliminary Analysis}

A previous analysis of the data revealed that there were missing values in 10 cases and 6 multivariate outliers $\left(\mathrm{D}^{2}=\mathrm{p} 1<0,01, \mathrm{p} 2<0,01\right)$. These participants were removed before conducting any further analysis ${ }^{21,23}$, itemlevel descriptive statistics (for all samples) indicated no deviations from univariate normality; i.e. skewness values ranged from -3 to 3 ; kurtosis values ranged from -7 to $7^{23}$.

Regarding the adjustment of the data to the measurement models, as can be seen in Table 1, all measurement models adjusted to the data, according cut-off values adopted in the methodology $y^{21,23,24}$ and shows also evidence of robustness, since the measurement model values are very close to the results of the adapted version 7 . Still, measurement models shows appropriate values of internal consistency regarding composite reliability $(\mathrm{CR})$, since the values of all samples are $\geq 0,70$. Problems occur regarding the convergent validity, on the general model, male and the nature sports samples, because the AVE values are less than to the value adopted in methodology $(\mathrm{AVE} \geq 0,50)$. The remaining samples do not show convergent validity problems, because the AVE values were equal or high to 0,50. Furthermore, in all measurement models, the standardized factorial loadings of the items (all statistically significant for a $\mathrm{p}<0,05$ ) show factorial validity; all items are $\geq 0,50$, thereby explaining at least $25 \%$ of the latent factor variance ${ }^{21}$.

As can be seen in Figure 1 (general model) that all the items show an adjusted factorial loadings above 0,50 (all statistically significant for a $\mathrm{p}<$ $0,05)$, fluctuating between 0,58 to 0,87 , and explains at least $25 \%$ of the latent factor variance ${ }^{21}$.

As can be seen in Table 2, enjoyment presents significant and negative correlations with all types of controlled motivation: amotivation, external and introjected regulation. Specifically, it presents a weak correlation on amotivation and a moderate correlation with both external regulation and

Table 1. Fit indexes of the measurement models (including existing versions).

\begin{tabular}{|c|c|c|c|c|c|c|c|c|c|c|}
\hline $\begin{array}{l}\text { Measurement } \\
\text { Models }\end{array}$ & $\chi^{2}$ & $d f$ & SRMR & NNFI & CFI & RMSEA & $90 \% \mathrm{Cl}$ & $\mathrm{CR}$ & \ij & AVE \\
\hline${ }^{1}$ Model & $24,164^{\star \star}$ & 20 & - & 0,98 & 0,98 & 0,04 & $0,00-0,08$ & 0,93 & $>0,70$ & $>0,50$ \\
\hline${ }^{2}$ Model & $181,96^{*}$ & 20 & 0,04 & 0,94 & 0,96 & 0,07 & $0,06-0,08$ & 0,88 & $0,58-0,87$ & 0,49 \\
\hline${ }^{3}$ Model & $113,27^{*}$ & 20 & 0,03 & 0,95 & 0,97 & 0,07 & $0,06-0,08$ & 0,88 & $0,61-0,78$ & 0,49 \\
\hline${ }^{4}$ Model & $67,59^{*}$ & 20 & 0,03 & 0,94 & 0,96 & 0,07 & $0,06-0,09$ & 0,90 & $0,60-0,87$ & 0,52 \\
\hline${ }^{5}$ Model & $42,32^{* *}$ & 20 & 0,04 & 0,96 & 0,98 & 0,06 & $0,04-0,08$ & 0,87 & $0,50-0,87$ & 0,47 \\
\hline${ }^{6}$ Model & $130,14^{\star}$ & 20 & 0,04 & 0,94 & 0,96 & 0,07 & $0,06-0,08$ & 0,89 & $0,63-0,79$ & 0,50 \\
\hline
\end{tabular}

Legend: $\chi^{2}=$ chi-squared; $\mathrm{df}=$ degrees of freedom; SRMR = Standardized Root Mean Square Residual; NNFI = Non-Normed Fit Index; CFI $=$ Comparative Fit Index; RMSEA = Root Mean Squared Error of Approximation; $90 \% \mathrm{Cl}=$ confidence interval of RMSEA;CR $=$ Composite Reliability; $\lambda \mathrm{ij}=$ Standardized Factor Loadings; AVE= Average Variance Extracted; ${ }^{1}$ Original Model Mullen et al. ${ }^{7}$ (8 items $/ 1$ factor); ${ }^{2}$ Portuguese version Model (8 items/1 factor); ${ }^{3}$ Model: the Portuguese version model with male sample; ${ }^{4}$ Model: the Portuguese version model with female sample; ${ }^{5}$ Model: the Portuguese version model sample with nature sports; ${ }^{6}$ Model: the Portuguese version model with swimming sample; $p<0,01 ;{ }^{\star *} p \geq 0,01$ 


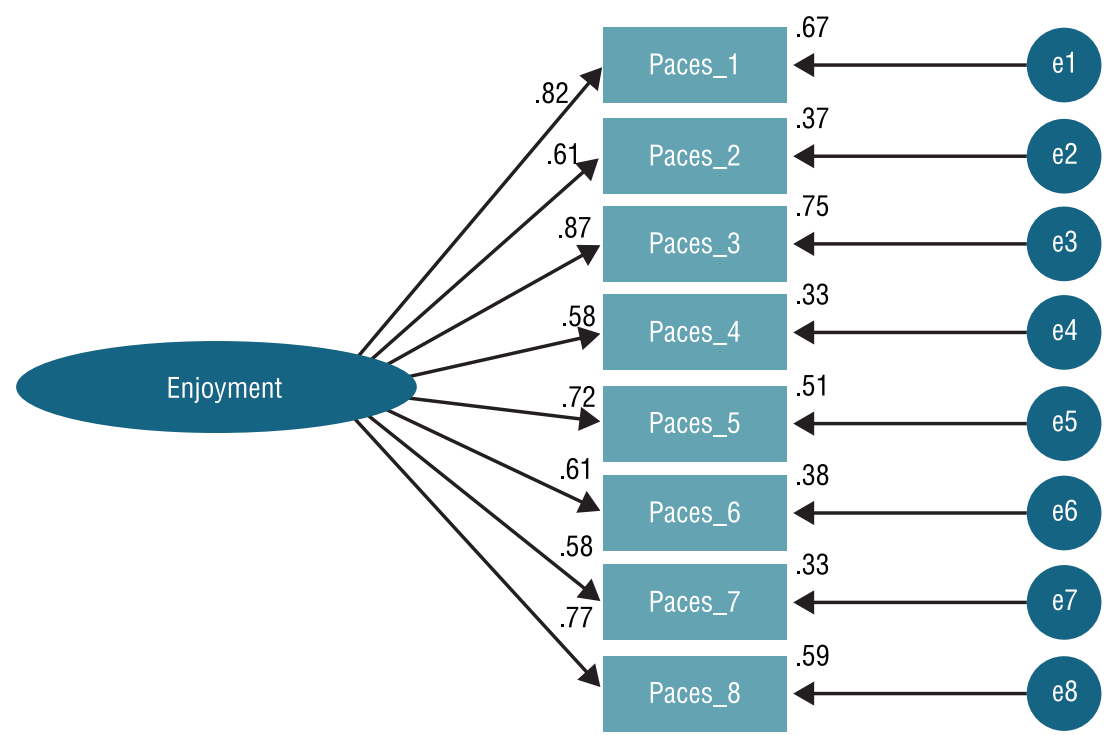

Figure 1. Standardized individual parameters (covariance factors, factorial loadings and measurement errors), all of which were significant in the measurement model (one factor and 8 items) for the Portuguese version from Mullen et al. ${ }^{7}$

introjected regulations. On the other hand, it shows that, in a general way, it has positive and significant correlations with all types of autonomous motivation: identified regulation, integrated and intrinsic motivation. Specifically, it shows a moderate correlation with the integrated regulation and a strong correlation with both the identified regulation and intrinsic motivation.

Table 2. Correlations between enjoyment (PACES) and motivational regulation (BRSQp)

\begin{tabular}{|c|c|c|c|c|c|c|c|}
\hline & 1 & 2 & 3 & 4 & 5 & 6 & 7 \\
\hline 1.Enjoyment & 1 & $-0.25^{\star *}$ & $-0.42^{* *}$ & $-0.38^{\star *}$ & $0.82^{*}$ & $0.62^{*}$ & $0.90^{*}$ \\
\hline 2.Amotivation & - & 1 & $0.68^{\star \star *}$ & $0.54^{\star \star}$ & $-0.24^{* *}$ & $-0.33^{\star \star}$ & $-0.38^{* *}$ \\
\hline 3.External Regulation & - & - & 1 & $0.73^{\star \star}$ & $-0.24^{* *}$ & $-0.36^{* *}$ & $-0.44^{* *}$ \\
\hline 4.Introjected Regulation & - & - & - & 1 & $-0.90^{* *}$ & $-0.18^{* *}$ & $-0.57^{\star *}$ \\
\hline 5.Identified Regulation & - & - & - & - & 1 & $0.59^{* *}$ & $0.34^{\star *}$ \\
\hline 6.Integrated Regulation & - & - & - & - & - & 1 & $0.51^{* *}$ \\
\hline 7.Intrinsic Motivation & - & - & - & - & - & - & 1 \\
\hline
\end{tabular}

Legend: ${ }^{\star} p \leq 0.01 ;{ }^{* *} p \leq 0.05$

As can be seen in Table 3. the model is invariant across sports (swimming vs nature sports) and genders (male vs female). meaning that the values found indicate the following: the same amount of manifest variables (items) is present in the amount of latent variables (factors) (configural invariance); the PACES factor from the version of Mullen et al. ${ }^{7}$ has the same meaning in the four groups (metric invariance); the comparison of the observable and latent means is valid across groups (strict-invariance); support is given to the comparison between the observed items(residual invariance). However. in this last case the assumption was not verified. 
Table 3. Fit indexes for the invariance of the measurement model of the PACES across genders and swimming and nature sports

\begin{tabular}{lccccccc}
\hline Models & $\chi^{2}$ & $\mathrm{df}$ & $\Delta \chi^{2}$ & $\Delta \mathrm{df}$ & $\mathrm{p}$ & $\mathrm{CFI}$ & $\Delta \mathrm{CFI}$ \\
\hline Male - Female & & & & & & & \\
Configural Invariance & 180.88 & 40 & - & - & - & 0.966 & - \\
Measurement Invariance & 186.72 & 47 & 5.83 & 7 & 0.559 & 0.965 & 0.001 \\
Scale Invariance & 186.73 & 48 & 5.85 & 8 & 0.664 & 0.965 & 0.001 \\
Residual Invariance & 217.57 & 56 & 36.68 & 16 & 0.006 & 0.961 & 0.005 \\
Swimming - Nature Sports & & & & & & & \\
Configural Invariance & 141.39 & 40 & - & - & - & 0.971 & - \\
Measurement Invariance & 155.26 & 47 & 13.86 & 7 & 0.054 & 0.969 & 0.002 \\
Scale Invariance & 168.27 & 48 & 26.87 & 8 & 0.001 & 0.966 & 0.005 \\
Residual Invariance & 296.87 & 56 & 155.47 & 16 & 0.000 & 0.933 & 0.038 \\
\hline
\end{tabular}

Legend: $\chi^{2}=$ chi-squared; $\mathrm{df}=$ degrees of freedom; $\Delta \chi^{2}=$ differences in the value of chi-squared; $\Delta d f=$ differences in the degrees of freedom; CFI = Comparative Fit Index; $\Delta C F I=$ differences in the value of the Comparative Fit Index

\section{DISCUSSION}

The aim of this study was to translated and validated PACES ${ }^{7}$ for the Portuguese population. Measurement invariance across gender and sports (nature sports and swimming). as well as. the external validity of PACES. through a correlational analysis between PACES and BRSQ p. extends the scientific evidence and contributes to the dissemination of measurement instruments already elaborated on with other populations were analysed.

Concerning the psychometric properties of the translation and validation of the PACES from Mullen et al. ${ }^{7}$ for Portuguese population. results showed that the initial model (i.e.. one factor/eight items). was adjusted to the data ${ }^{21.23 .24}$. For the remaining samples. the measurement model revealed similar values to those of the final model (with greater values on the nature sports sample). This evidence means that the obtained psychometric properties show the adequacy of the translation and validation. and the factorial structure of $\mathrm{PACES}^{7}$ for sports domain (nature and swimming domains) has good indexes of adjustment. Similar results have been found in recent study in exercise domain ${ }^{26}$.

According to Hair et al. ${ }^{21}$. these results are mainly related to the validity of the construct: whenever a set of items reflects the theoretical latent construct that it is supposed to measure. every item presents a relevant factorial weight on the factor reflecting the original model. Moreover. this evidence set proves the psychometric robustness inherent in the version of Mullen et al. ${ }^{7}$. Corroborating with the Mullen et al. ${ }^{7}$ conclusions shows this instrument's validity and reliability for researchers studying other populations.

PACES was also shown to have good external validity criteria. since enjoyment correlated significantly and negatively with all types of controlled motivation (amotivation. external and introjected regulation) and both positively and significantly with all types of autonomous motivation 
(identified and integrated regulation and intrinsic motivation). underlying to the SDT framework. one of the most used theories within the sports context $\mathrm{t}^{13}$. Similar results were found in other studies showing that all types of autonomous motivation correlate positively and significantly with enjoyment. and all types of controlled motivation correlates negatively with enjoyment ${ }^{8.12 .13 .27}$.

Specifically. the higher correlations are between enjoyment. identified regulation $(r=0.82)$. and intrinsic motivation $(r=0.90)$ which means that. when the athletes practice their sport by identifying themselves with it. they have a tendency to value it. since they perceive higher levels of enjoyment. however in this state. although being autonomous. the subject still executes the activity by its instrumental value. Notwithstanding. the high correlational pattern found between enjoyment and intrinsic motivation can be conceptually explained by the SDT; the intrinsic motivation itself represents the enjoyment inherent in the practice of activity. not for the instrumental value. but for the pleasure/satisfaction that is underlying. in this way self-perceiving high levels of enjoyment ${ }^{13}$. Teques et al. ${ }^{26}$ also find moderate positive relationships between more self-determined forms of behavioural regulations. such as identified regulation and intrinsic motivation. and enjoyment. and moderate negative relationships between external regulation and enjoyment. These findings are in line with previous studies on the facilitative role of autonomously self-regulated behaviour in enjoyment in sport ${ }^{27}$.

These evidences show the role of motivation within the sports context and its theoretical importance underlying to the self-determination theory framework. in this case as regards enjoyment ${ }^{8.12}$. At the same time. the evidences highlight that enjoyment is a consequence of motivation. which means that the high levels of enjoyment are associated with high levels of motivation (quality of motivation) ${ }^{12}$. When this happens. the subjects persist more in practice and have less intention to sport dropout ${ }^{3}$.

Concerning the internal consistency all the factors were revealed to have a good composite reliability value of $\geq 0$. 70. fluctuating between 0.87 and $0.90^{21}$. Similar results were found in the original version ${ }^{14}$. as well as in later validations ${ }^{5.710 .16}$. demonstrating that the enjoyment factor measures the theoretical construct that it intends to measure. Relative to convergent validity. minor issues are verifiable on the general model and on the sample of the male gender and nature sports: the AVE value is below the recommended value ( $\mathrm{AVE} \geq 0.50$ ) in the majority of the literature ${ }^{21}$.

However. all the factorial loadings on these samples are high or equal to 0.50 and are significant to the respective factor. According to Hair et al. ${ }^{21}$. this is indicative of good convergent validity for the present study. In light of the analysis of the modification indexes. none of the items presented residual values that were too high. this evidence being an indicator of convergent validity ${ }^{23}$. The remaining samples did not show issues with the convergent validity since the AVE value was high or equal to $0.50^{21}$.

Regarding the multi-group analysis. the results support the measure- 
ment equivalence across four samples: the theoretical construct underlying to the questionnaire (i.e.. enjoyment) on the specific context of sport is conceptualized in the same way across genders (i.e.. male and female) and sports (i.e.. nature sports and swimming). Having in consideration the analysis assumptions of the model's invariance ${ }^{23.25}$. we can state that for the genders and nature sports and swimming that: a) the purposed theoretical structure (the same manifested variables - items that are explained by the same latent variable - factor) maintains (configural invariance); b) that the factorial loadings of the items are equivalent (metric invariance). meaning that the items show the same importance to the factor independently of the group; c) that comparisons of results across genders and these two sports can be made using the same questionnaire (i.e. scalar invariance). the linguistic equivalence (semantics) is valid and the operational applicability of the instrument substantiates the importance of enjoyment in the sports context. Finally. regarding the strict invariance. this assumption was not verified in the present study. although this last criterion is not indicative of lack invariance of the model. and some authors even consider that it is irrelevant to analyse it due to it being too restrictive ${ }^{23}$.

Notwithstanding. Mullen et al. ${ }^{7}$ also proved that the measurement model underlying to PACES was invariant across time (longitudinal invariance) and across exercise programs. Teques et al. ${ }^{26}$ also have been showed invariance across gender in exercise domain. These results prove the psychometric robustness is underlying to these items on the assessment of enjoyment.

\section{CONCLUSION}

In conclusion. with these results. we can state that the measurement model (one factor/ eight items) of the translation and validation of PACES from Mullen et al. ${ }^{7}$ for the Portuguese population has very acceptable psychometric properties. and is able to be used in this way. without reservation. to assess enjoyment in a sports context. specifically in swimming and nature sports. These evidences support the conclusions of Mullen et al. ${ }^{7}$ meaning that this instrument can be used with a high degree of validity and reliability by the researchers. However. sharing the opinion of Moreno-Murcia et al. ${ }^{8}$ who reminds us that the validation of instruments is a lengthy process. features several difficulties and should not be limited to just a single study. so we feel it is highly advisable that further studies with this scale using other sports and age-groups. should be made and other invariance analyses of this measurement model with other variables as well (e.g.. motivational climate. basic psychological needs) or cultures (e.g.. invariance throughout countries) should be done. make it more robust at a psychometric level.

Cross-cultural adaptation is a fundamental process whenever there is an intention of using an instrument that was developed for a specific type of population on a different population ${ }^{28}$. In fact. the application of a new instrument to a different cultural group implies more than its translation. 
application and comparison of results. According to He and Van de Vijver ${ }^{29}$. cross-cultural studies should be presented together with all psychometric evaluation stages. which requires a substantial sample. an adequate research design and must demonstrate that the construct. method and obliquity of the items do not differ between version. Researchers should explore the structure of the constructs and the adequacy of the items. making sure they have the same cultural significance ${ }^{28}$. For this reason. future studies are needed in order to understand the PACES model invariance across countries (e.g.. Portugal and Brazil or among others). such has been done by several authors ${ }^{28.30}$.

Furthermore. also suggests other studies with structural equation models. testing the enjoyment both as an antecedent and as a consequence of behaviour. since this concept is transversal and important to all areas of knowledge. Finally. it is important to emphasize that not only is a Portuguese version of the enjoyment measurement model available within a sports context. filling a gap that existed to date. but also study of the instrument will allow coaches and teachers to obtain valid and reliable indicators of enjoyment by their sport's athletes. which can be useful for planning the sessions and for screening factors that can lead to other consequences originating in lack of enjoyment (e.g.. sports dropouts).

\section{REFERENCES}

1. Kendzierski D. Morganstein MS. Test. revision. and cross-validation of the physical activity self-definition. J Sport Exerc Psychol 2009; 31(4): 485-504

2. Raedeke TD. The relationship between enjoyment and affective responses to exercise. J Appl Sport Psychol 2007; 19(1):105-115.

3. Quested E. Ntoumanis N. Viladrich C. Haug E. Ommundsen Y. Van Hoye A. Mercé J. et al. Intentions to drop out of youth soccer: a test of the basic needs theory among European youth in five countries. Int J Sport Exerc Psychol 2013;11(4): 395-407.

4. Jeakuc D. Voelke M. Wagner MO. Mewes N. Wall A. Reliability. Validity and Measurement Invariance of the German version of the Physical Activity Enjoyment Scale. J Pediatr Psychol 2012; 38(1): 104-115

5. Motl RM. Dishman RK. Sauders R. Dowda M. Felton G. Pate RR. Measuring enjoyment of physical activity in adolescent girls. Am J Prev Med 2001; 21(2):110-117.

6. Heesch KC. Mâsse LC. Dunn AL. Using rash modeling to re-evaluate three scales related to physical activity: enjoyment. perceived benefits and perceived barriers. Health Educ Res 2006 21(1):58-72

7. Mullen SP. Olsen EA. Philips SM. Szabo AN. Wójcicki RT. Mailey EL. et al. Measuring enjoyment of physical activity in older adults: invariance of the physical activity enjoyment scale (paces) across groups and time. Int J Behav Nutr Phys Act 2001; 8: 103.

8. Moreno-Murcia J. González-Cutre D. Martínez C. Alonso N. López M. Psychometric properties of the Physical Activity Enjoyment Scale (PACES) in the Spanish context. Estud Psicol 2008; 29 (2): 173-80.

9. McArthur LH. Raedeke TD. Race and sex differences in college student physical activity correlates. Am J Health Behav 2009; 33 (1): 80-90

10. Crocker P. Bouffard M. Gessaroli. ME. Measuring enjoyment in youth sport settings: A confirmatory factor analysis of the Physical Activity Enjoyment Scale. J Sport Exerc Psychol 1995; 17 (2): 200-5

11. Nahas MV. Goldfine B. Collins. MA. Determinants of physical activity in adolescents and young adults: The basis for high school and college physical education 
to promote active lifestyles. Physical Educator 2003; 60 (1): 42-56

12. Deci EL. Ryan RM. Self-Determination theory and the facilitation of intrinsic motivation. social development. and well-being. Am Psychol 2000.55 (1):68-78.

13. Álvarez MS. Balaguer I. Castillo I. Duda JL. Coach autonomy support and quality of sport engagement in young soccer players. Span J Psychol 2009; 12 (1):35-44

14. Kendzierski D. De Carlo KJ. Physical Activity Enjoyment Scale: Two validation studies. J Sport Exerc Psychol 1991; 13 (1): 50-64

15. Marsh HW. Positive and negative global self-esteem: a substantive distinction or artifacts? J Pers Soc Psychol 1996; 70 (4): 810-9

16. Moore JB. Yin Z. Hanes. J. Duda JL. Gutin B. Barbeau P. Measuring Enjoyment of Physical Activity in Children: Validation of the physical activity enjoyment scale. J Appl Sport Psychol 2009; 21(1): 116-29

17. Kline RB. Principles and practice of structural equation modeling (3TH ed.). Nova York:Guilford press; 2011

18. Kendzierski D. Furr MR. Schiavani. J. Physical Activity self-definitions: correlates and perceived criteria. J Sport Exerc Psychol 1998; 20 (2): 176-93

19. Londsdale C. Hodge K. Rose EA. The Behavioral Regulation in Sport Questionnaire (BRSQ): Instrument Development and Initial Validity Evidence. J Sport Exerc Psychol 2008;30 (3): 323-55

20. Monteiro D. Moutão J. Cid L. Validation of the behavioural regulation in sport questionnaire in a sample of Portuguese athlete. Rev Psicol Deporte in press; 27 (1).

21. Hair J. Black W. Babin B. Anderson R. Multivariate data analysis (7th ed.). New Jersey: Pearson Educational; 2014

22. Vallerand. RJ. Toward a methodology for the transcultural validation of psychological questionnaires: Implications for research in the French language. Can Psychol 1989; 30 (4): 662-80.

23. Byrne B. Structural equation modeling with AMOS: Basic concepts. applications. and programming (2nd.ed). New York: Routledge. Taylor Francis; 2010

24. Marsh HW. Hau K. Wen Z. In search of golden rules: Comment on hypothesistesting approaches to setting cutoff values for fit indexes and dangers in overgeneralizing Hu and Bentler's (1999) findings. Struct Equ Modeling 2004; 11(1): 320-41

25. Cheung GW. Rensvold RB. Evaluating goodness-of-fit indexes for testing measurement invariance. Struct Equ Modeling 2002; 9 (2): 233-55

26. Teques P. Calmeiro L. Silva C. Borrego C. Validation and adaptation of the physical activity enjoyment scale (PACES) in fitness group exercisers. J Sport Health (in press).

27. Moreno-Murcia J. San Róman M. Galindo C. Alonso N. González-Cutre. D. Peers' influence on exercise enjoyment: A self-determination theory approach. J Sports Sci Med 2008; 7(1): 23-31.

28. Vlachopoulos S. Asci H. Cid L. Ersoz G. González-Cutre D. Moreno-Murcia J. et al. Cross-cultural Invariance of the Basic Psychological Needs in Exercise Scale and Latent Mean Differences Among Greek. Spanish. Portuguese. and Turkish Samples. Psychol Sport Exerc 2013; 14(5): 622-31.

29. He J. van de Vijver F. Bias and Equivalence in Cross-Cultural Research. Online Read Psychology Cult 2012;2(2): 1111.

30. Cid L. Lettnin C. Stobaus C. Monteiro D. Davoglio T. Moutão J. Cross-cultural validation of the basic psychological needs in physical education between Portugal and Brazil Samples. Span J Psychol 2016; 19 (5): 1-10.

\section{CORRESPONDING AUTHOR}

Diogo Manuel Teixeira Monteiro Escola Superior de Desporto de Rio Maior do Instituto Politécnico de Santarém

Av. Dr. Mário Soares. 10. 2040-413

Rio Maior. Portugal E-mail:diogomonteiro@esdrm. ipsantarem.pt 